\title{
Changes in precipitation recycling over arid regions in the Northern Hemisphere
}

\author{
Ruolin $\mathrm{Li}^{1}$ - Chenghai Wang ${ }^{1} \cdot \mathrm{Di} \mathrm{Wu}{ }^{1}$
}

Received: 5 December 2015 / Accepted: 12 October 2016 /Published online: 5 November 2016

(C) The Author(s) 2016. This article is published with open access at Springerlink.com

\begin{abstract}
Changes of precipitation recycling (PR) in Northern Hemisphere from 1981 to 2010 are investigated using a water recycling model. The temporal and spatial characteristics of recycling in arid regions are analyzed. The results show that the regional precipitation recycling ratio (PRR) in arid regions is larger than in wet regions. PRR in arid regions has obvious seasonal variation, ranging from more than $25 \%$ to less than $1 \%$. Furthermore, in arid regions, PRR is significantly negatively correlated with precipitation (correlation coefficient $r=-0.5$, exceeding the $99 \%$ significance level). Moreover, the trend of PRR is related to changes in precipitation in two ways. PRR decreases with increasing precipitation in North Africa, which implies that less locally evaporated vapor converts into actual precipitation. However, in Asian arid regions, the PRR increases as precipitation reduces, which implies that more locally evaporated vapor converts into rainfall. Further, as PRR mainly depends on evapotranspiration, the PRR trend in Asian arid regions develops as temperature increases and more evaporated vapor enters the atmosphere to offset the reduced rainfall.
\end{abstract}

\section{Introduction}

Precipitation over the global land surface has shown a decreasing trend from -1.54 to $-2.12 \mathrm{~mm} \mathrm{year}^{-1}$, while it has increased

Chenghai Wang

wch@lzu.edu.cn

1 Key Laboratory of Arid Climate Change and Disaster Reduction of Gansu Province, College of Atmospheric Sciences, Lanzhou University, Lanzhou, Gansu Province 730000, China in north of $30^{\circ} \mathrm{N}$ in Northern Hemisphere during the past 30 years (IPCC 2014). Evaporation increased from the early 1980 s to the late 1990 s, and land air humidity decreased from the 1970s (Trenberth 1998a). However, the frequency of heavy precipitation has increased, and there have been more drought events in regions such as the Mediterranean and West Africa from the 1970s but fewer in central North America and northwest Australia from the 1950s (Bisselink and Dolman 2008). Changes in precipitation are related to atmospheric precipitable water, and regional precipitable water can be changed by variations in water vapor transport and regional evaporation (Eltahir and Bras 1996). This means that changes in water recycling are a regional feature under global warming, and the variability of water recycling may lead to changes in precipitation (IPCC 2014). Studies show that atmospheric water recycling has changed with global warming, and evaporation will also change as the temperature increases (Trenberth 1998a).

There are two components of the total water vapor leading to precipitation, local evaporation (recycling) and external water vapor transportation (advection) (Burde and Zangvil 2001). In general, arid regions are located far from the ocean and moisture advection is low. Water recycling is a key component in precipitation in arid regions, linking the land surface and the atmosphere (Dominguez and Kumar 2008). Studies (Willett et al. 2008; Smith et al. 2012) show that atmospheric vapor and precipitation increased over the past 20 years (1991-2010), but the increasing rate from climate model simulations is lower than the observations (Wentz et al. 2007). The change of vapor in the atmosphere will lead to variations of precipitation and water recycling (Eltahir and Bras 1994).

To estimate the proportion of recycling precipitation in total rainfall, recycling models have been proposed. A simple twodimensional model was developed to calculate the precipitation recycling ratio (PRR) in the west of the former Soviet Union (Budyko 1974). A two-dimensional month-scale 
precipitation recycling model was developed by Brubaker et al. (1993) and was used to estimate the variation of recycling ratio in North America, Europe, the Amazon basin, and the Western Sahara. The recycling ratios in Europe from these two models were compared and were found to be similar except in summer. The difference was due to the different regions investigated (Brubaker et al. 1993). The results estimated by Brubaker et al. show that in Europe the maximum recycling ratio is found in June (about $31 \%$ ) while the minimum occurs in February (about $0 \%$ ). And in North America, the recycling ratio was between 15 with $34 \%$, and the maximum appears in June and October. In contrast, in South America, the maximum recycling ratio is $32 \%$ in December, and the minimum is $14 \%$ in June (Brubaker et al. 1993). The maximum recycling ratio in the Yangtze River basin estimated from this model was $19 \%$ in autumn, the minimum was $3 \%$ in spring, and the average value was about $10 \%$ (Kang et al. 2004). Another new dynamic recycling model (DRM) was developed based on Burde and Zangvil's model (Dominguez et al. 2006). Moisture variability is considered in this model, and the recycling ratio is estimated on a daily scale. The recycling ratio of the Yangtze River and the Yellow River basin was estimated (Kang et al. 2005) using the model developed by El-tahir et al. (1992). The recycling ratio had strong periodicity in the Yangtze River basin. The maximum was $40 \%$ in August, September, and October and the minimum was less than $25 \%$ in May, June, and July (Kang et al. 2004, 2005). The result of minimum was $20 \%$, larger than the values estimated by $\mathrm{Yi}$ and Tao (1997). Differences between the models used and the regions chosen could explain this discrepancy. The average recycling ratio was $19 \%$ in the Yellow River basin, about $15 \%$ in the upstream basin and greater than $30 \%$ in the downstream basin, with the maximum in August and the minimum in November, December, and January (Kang et al. 2005). Using an improved recycling model based on Eltahir and Bras (1996), Fu et al. (2006) found that $30 \%$ of the precipitation originated from evaporation in the Yangzi River basin in the 1998 rainy season. The recycling ratio varied strongly on a 10-day scale, with a maximum of $67.8 \%$ and a minimum of $0.8 \%$, showing that the land was significantly sensitive to variability in hydrology and landatmosphere interactions in this region.

Precipitation trends have a distinctive spatiotemporal distribution in arid region. Observations show that rainfall has increased in some arid regions (such as central North America and northwest Australia) but decreased in others (West Africa), and the precipitation frequency became complex (IPCC 2014), which implies significant changes in the contribution of local recycling vapor to precipitation in arid regions. For example, the precipitation recycling ratio in the east of the Qinghai-Tibet Plateau increased significantly in the period 1979-2006, with precipitation also increasing. In the same period, the ratio decreased but precipitation still increased in the west of the plateau (Wang and Guo 2012; Guo and Wang 2014), indicating that the effect of PRR on total precipitation in the region is uncertain.

To assess the precipitation recycling reliably, an essential issue is the estimation of the role of evaporation in precipitation. In the Mississippi basin, the evaporation was less than $10 \%$ of the total precipitation (Benton and Estoque, 1954). An investigation of the summer moisture budgets in central North America in 1979 found that the main source of daytime precipitation was local evaporation (Zangvil et al. 1993). A moisture budget analysis of the Brahmaputra basin using the moisture conservation equation showed that precipitation was greater than evaporation in summer but less than the evaporation in autumn and winter (Zhang and Tao 2001). The estimation of precipitation recycling depends on the model, and evaporation is a crucial component of the model. A new two-dimensional precipitation recycling model that considers the inhomogeneity and imbalance of the moisture flux was developed by Burde and Zangvil (2000). In arid regions in Africa, result of the recycling ratio from Trenberth (1998a, b) is $12-20 \%$ and the maximum occurs in December, January, and February (DJF). The recycling ratio in the Central U.S. Plains calculated using North American Regional Reanalysis Data (NARR) reanalysis data simulated by DRM ranges from 7 to $30 \%$ (Domiguez and Kumar 2008). But if the data (GEOS1) and method are changed, the value can reach $60 \%$ in the same region (Bosilovich and Schubert 2002). Brubaker et al. (1993) used mass balance, neglecting changes in atmospheric moisture to calculate evapotranspiration and estimated the recycling ratio as $30 \%$ in Central North America and $15 \%$ in Africa. However, if GSWP-2 data are used (Dirmeyer et al. 2009), the values are 10 and $2 \leq \%$, respectively.

Precipitation recycling is an important process in arid regions, but it still has uncertainties due to the estimation approach in arid regions, and this uncertainty comes from the lack of observational data such as evapotranspiration and from the models. Evapotranspiration data are available from NCEP/ NCAR Reanalysis 1 and ERA-interim data, but they are still fairly uncertain. The two-dimensional model proposed by Brubaker et al. (1993) is considered to be a convenient and reliable estimation method, but the model is sensitive to evapotranspiration. For an accurate calculation of PRR, a more reliable estimation method should be used. Penman (1948) proposed the combination equation to predict evapotranspiration, in which not only radiation and aerodynamics but also the land surface condition are considered. The Penman method was improved by Shuttleworth (1993) and 
Dingman (1994) and can be adapted for different land surface conditions such as open water, bare soil, and grass.

In this study, we try to estimate the precipitation recycling (PR) and its variability on large scale, compare features in different arid regions to understand precipitation properties in arid regions, and attempt to understand the recycling precipitation by analyzing the trend of PR in the period 1981-2010 and by comparing precipitation changes in arid regions, with the aim of improving our knowledge of the characteristics of precipitation period and change in arid regions. The rest of this paper is organized as follows. A description of the methods and datasets used are given in Section 2. In Section 3, the global spatial characteristics of PR and related variables are discussed. The temporal variation in arid regions is analyzed in Section 4. It includes the annual and two seasonal values (Dec Jan Feb (DJF), and Jun Jul Aug (JJA)) of estimates of the recycling ratio and compares these with precipitation and other meteorological variables. The conclusions are given in Section 5 .

\section{Approach and data description}

The arid region definitions are adapted from Hulme and Marsh (1990) and Bisselink and Dolman (2008) that use the relation between precipitation and evapotranspiration (Fig. 1) to express the location of the main sinks and sources of atmospheric water vapor (Bisselink and Dolman 2008). If the evapotranspiration is greater than precipitation, it means it is the main source of water vapor and the region can be defined as hydrologically arid and vice versa. Accordingly, the main arid regions are the boxes shown in Fig. 1 and this study will focus on precipitation recycling in North Africa (NAF), West Asia (WA), China-Mongolia (CM), and North America (NA) in the Northern Hemisphere.
The model proposed by Brubaker et al. (1993) and improved by others (Schär et al. 1999; Burde and Zangvil 2001) is used to estimate the precipitation recycling, in which the equations of water vapor balance for each fraction of precipitable water are applied in their integral form to all the grids. The regional recycling of precipitation is indicated conceptually in Fig. 2. The box stands for one small grid box area $\Delta X$, and $Y$ represents the region. The horizontal arrows indicate the advective flux of water vapor into and out of $\Delta X . W$ is the amount of water vapor, ET is the evapotranspiration from the land surface, and $P$ is the total precipitation onto the land surface, made up of advective $\left(P_{\mathrm{a}}\right)$ and evapotranspirative $\left(P_{\mathrm{e}}\right)$ parts:

$P=P_{\mathrm{a}}+P_{\mathrm{e}}$

We also allow for a variation of the total atmospheric water content $W$ within the $\Delta X$, but this term is small, has a negligible impact upon the results, and is only considered for internal consistency. The associated budget relationship for each region can then be written as:

$\Delta W=\mathrm{IN}-\mathrm{OUT}+\mathrm{ET}-P$

Here, all the flux terms are integrated over the time period under consideration (selected as 1 month), and $\Delta W$ denotes the integrated tendency of the atmospheric water content within the box. IN stands for the vapor advected into the region.

It is assumed for the computation of the local recycling ratio $(\beta)$, defined as the proportion of local recycling precipitation to total precipitation or local evaporation vapor to total vapor, that the two water fractions that originate from evapotranspiration within and outside of the box, respectively, are well mixed in space and time. Assuming a constant recycling ratio within each box allows us to easily determine $\beta$ from the associated water fluxes. Individual budget relations similar to (2) may be expressed for the two fractions of water that derive from evapotranspiration in the interior of the domain and from

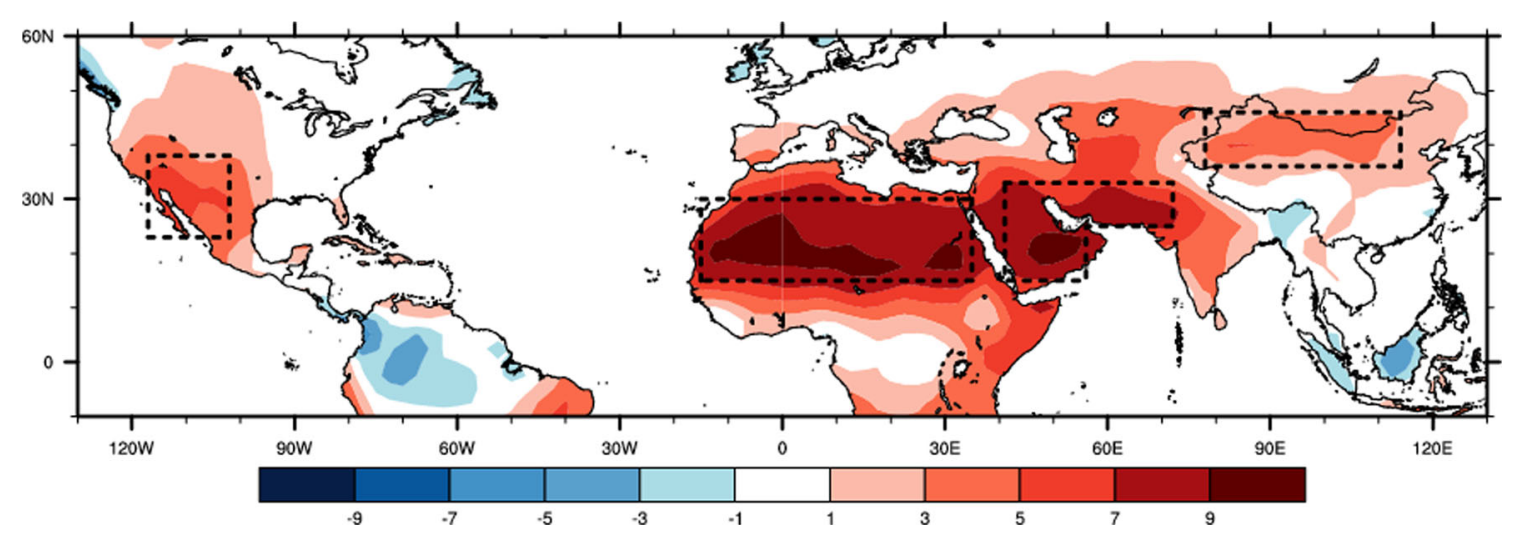

Fig. 1 The main arid regions (boxes) and annual evaporation minus precipitation (mm/day) calculated for the period 1981-2010 in Northern Hemisphere 


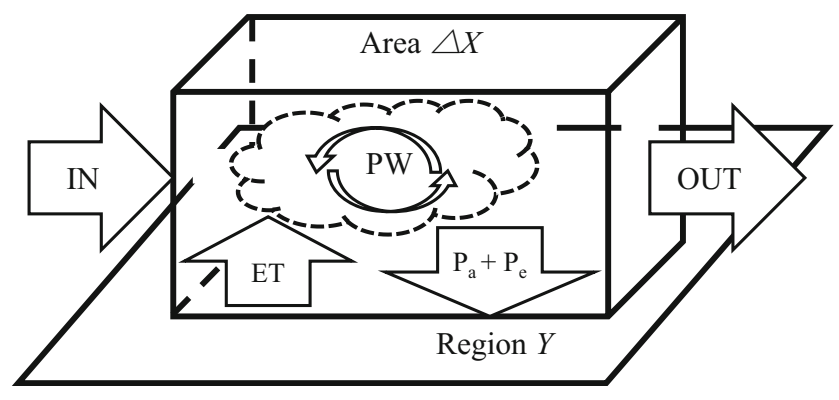

Fig. 2 Conceptual model of the precipitation and moisture fluxes in an atmospheric grid box, area $\Delta X$ within land region $Y$. For variable abbreviations, see text (adapted from Brubaker et al. 1993)

atmospheric advection into the domain, respectively. For instance, for the budget of water that originates from within the box, the term IN disappears, while the terms OUT, $P$, and $\Delta W$ appear with a factor $\beta$, consistent with the assumption of a uniform recycling ratio. The two budgets are then given by:

$\Delta W \beta=-\mathrm{OUT} \cdot \beta+\mathrm{ET}-P \cdot \beta$

$\Delta W \cdot(1-\beta)=\mathrm{IN}-\mathrm{OUT} \cdot(1-\beta)-P \cdot(1-\beta)$

Solving for $\beta$ and substituting from (2) yields:

$\beta=\mathrm{ET} /(\mathrm{ET}+\mathrm{IN})$

According to the formula, we can treat $\beta$ as a measure of the local recycling of water vapor. Then, with this definition, in the region $Y$ consisting of $n$ grids, the regional PRR may be calculated as:

$\mathrm{PRR}=\frac{P_{\mathrm{e}}}{P}=\frac{\sum_{i=1}^{n} \beta_{i} \cdot P_{i} \cdot \Delta X_{i}}{\sum_{i=1}^{n} P_{i} \cdot \Delta X_{i}}$

and the recycling precipitation (RP) in the region being studied is:

$\mathrm{RP}=P \cdot \mathrm{PRR}$

The wind and humidity data used in this study are from the NCEP/NCAR Reanalysis 2 Data monthly reanalysis dataset, with 17 pressure levels and $2.5^{\circ} \times 2.5^{\circ}$ horizontal resolution. The precipitation data are from the Global Precipitation Climatology Project monthly precipitation dataset (GPCP) from 1979 to the present, which combines observations and satellite precipitation data into $2.5^{\circ} \times 2.5^{\circ}$ global grids.

ET, defined as land surface water evaporation and plant transpiration (Thornthwaite 1948), is a crucial variable in the precipitation recycling process, while it is also a difficult factor to observe. In earlier research, most estimates of ET (Brubaker et al. 1993; Wang and Guo 2012; Guo and Wang 2014) were from mass balance by neglecting changes in atmospheric moisture, that is,

$\mathrm{ET} \approx P+\nabla \cdot \vec{Q}$

in which $P$ and $\nabla \cdot \vec{Q}$ refer to monthly regional mean values of precipitation and divergence of moisture flux, respectively. This estimate is only appropriate on large scales and even then is still unreliable. To get a credible precipitation recycling ratio, a more reliable ET estimation is needed that is based on radiation and dynamic conditions.

In this paper, evapotranspiration is estimated by Penman evaporation, as:

$\mathrm{ET}=\frac{\Delta}{\Delta+\gamma} \cdot \frac{\left(R_{\mathrm{n}}\right)}{\lambda}+\frac{\gamma}{\Delta+\gamma} \cdot \frac{6.43 \cdot\left(f_{\mathrm{U}}\right) D}{\lambda}$

where $R_{\mathrm{n}}$ is net radiation at the surface (MJ m ${ }^{-2}$ day $\left.^{-1}\right), \Delta$ is the slope of the saturation vapor pressure curve $\left(\mathrm{kPa}^{\circ} \mathrm{C}^{-1}\right), \gamma$ is the psychrometric coefficient $\left(\mathrm{kPa}^{\circ} \mathrm{C}^{-1}\right)$, and $f_{\mathrm{U}}$ is the wind function:

$f_{\mathrm{U}}=a_{\mathrm{U}}+b_{\mathrm{U}} u$

where $a_{\mathrm{U}}$ and $b_{\mathrm{U}}$ are wind function coefficients and $u$ is wind speed at $2 \mathrm{~m}$ height $\left(\mathrm{m} \mathrm{s}^{-1}\right)$; Penman (1948) gives the values $a_{\mathrm{U}}=1$ and $b_{\mathrm{U}}=0.536$. Here also, $D=\left(e_{\mathrm{s}}-e_{\mathrm{a}}\right)$ is vapor pressure deficit $(\mathrm{kPa}), e_{\mathrm{s}}$ is saturation vapor pressure, and $e_{\mathrm{a}}$ is actual vapor pressure.

According to the previous study (Valiantzas 2006), the first term on the right of Eq. (9) can be approximated as:

$\frac{\Delta}{\Delta+\gamma_{0}} \approx 0.125 \cdot \sqrt{T+9.5}$

Where $T$ is expressed in degrees Celsius.

The net radiation, $R_{\mathrm{n}}$, is computed as the difference between the incoming net short wave radiation, $R_{\mathrm{ns}}$, and the outgoing net long wave radiation, $R_{\mathrm{nL}}$ :

$R_{\mathrm{n}}=R_{\mathrm{nS}}-R_{\mathrm{nL}}$

The $R_{\mathrm{nL}}$ is computed as:

$R_{\mathrm{nL}}=f \varepsilon^{\prime} \sigma \cdot(T+273.2)^{4}$

where $f$ is an adjustment for cloud cover, $\varepsilon^{\prime}$ is net emissivity between the atmosphere and the ground, $\sigma$ is the StefanBoltzmann constant, and $T$ is the mean air temperature over the period studied.

The calculation of the incoming net short wave radiation is:

$R_{\mathrm{nS}}=(1-\alpha) \cdot R_{\mathrm{S}}$

where $\alpha$ is the reflection coefficient or albedo and $R_{\mathrm{S}}$ is measured or incoming solar radiation. 


\section{Spatial characteristics of precipitation recycling and related variables}

Figure 3a shows the annual global precipitable water (PW), which represents the total vapor in target region atmosphere, from 1981 to 2010. PW decreases with increasing latitude, and high precipitation is found in northern South America, north of Australia, in South Asia, and in Central Africa. Note that PW in arid regions is not necessarily less than in other regions; for example, the values in the Sahara desert, Arabian Peninsula, Central Asia, and Australia are no lower than in abundant rainfall regions such as Western Europe. The precipitation (Fig. 3b) also decreases with increasing latitude, but there are still maximums in Europe. Note the difference between PW and precipitation in arid regions. In some arid regions, such as Central and West Asia, the PW is abundant but rainfall is low, especially in summer. Thus, in arid regions, there is abundant precipitable water but the mechanism to convert it into rainfall is absent. Other important variables related to precipitation are ET and moisture flux (MF), the moisture transport. The annual average distributions of ET and MF are shown in subpanels $\mathrm{c}$ and $\mathrm{d}$ of Fig. 3, respectively. In Fig. 3d, the vectors show the paths of moisture transport and the color shading gives its magnitude. The evapotranspiration also generally decreases with increasing latitude (Fig. 3c). However, there are still maximums of MF in high latitudes; large amounts of moisture are transported into these regions. According to the Penman formula (Eq. 9), the regions of high ET are mainly in North Africa, West and Central Asia, Australia, and Central America. Note that in arid regions like West Asia and Central Asia, where the temperature is high but there is little soil moisture and vegetation, ET is no lower.

The annual global distribution of local recycling ratio $\beta$ is shown in Fig. 3e. The distribution is different from that of precipitable water and other variables. There are maximums zonally around the equator in the tropics and subtropics (close to $20 \%$ ). Maximums (more than $10 \%$ ) are also distributed in high southern subtropical regions, like South Africa, north of Australia, and central South America (about $18 \%$ ). In the Northern Hemisphere, the recycling ratios in Europe and West-Central Asia are larger than in other land regions (about $7 \%$ ). Note that $\beta$, unlike precipitation, is larger in arid regions like North Africa, Arabian Peninsula, Central Asia, and Australia than in regions with abundant rainfall. This indicates that the proportion of recycling precipitation in these regions is higher than in other regions, while the precipitation from advective vapor water is less important in these regions. The global recycling ratio distribution has also been calculated by Trenberth (1998a). Because of the lack of ET data in arid regions, they did not analyze the recycling of precipitation there. In other regions, however, the results from the present investigation are similar to theirs, with maximum in India, central South America, and South Africa. Trenberth (1998b) found that the centers of minimum recycled precipitation are mainly in Central-East Asia and Australia, which differs from our results; the different ET data used may be the reason.

In terms of the seasonal variations, in DJF, PW is more concentrated in low latitudes (Fig. 4a) and the precipitation is mainly in the Southern Hemisphere (Fig. 4b). In contrast, in JJA, maximums of PW (Fig. 5a) are more widespread, from low to middle latitudes, and more rainfall is concentrated in the Northern Hemisphere (Fig. 5b). The main areas of abundant rainfall are still in the tropical equatorial region. But MF in high latitudes in DJF (Fig. 4d) is larger than in JJA (Fig. 5d). This implies an important role of ET in total PW. In Northern Hemisphere winter (DJF), the average temperature is close to or below $0{ }^{\circ} \mathrm{C}$, which makes substantial ET impossible north of $40^{\circ} \mathrm{N}$. But the zonal moisture flux remains stable compared with the JJA and annual averages. This suggests that there is less recycling precipitation in the Northern Hemisphere winter. Figure $4 \mathrm{e}$ supports this view; the typical values of $\beta$ north of $40^{\circ} \mathrm{N}$ are below $3 \%$. Figure $4 \mathrm{c}$ is also consistent with negligible recycling precipitation here. At the same time, it is summer in the Southern Hemisphere, and the temperatures are higher than in the Northern Hemisphere, resulting in higher evapotranspiration from soil and vegetation. MF is less over Southern Hemisphere land (Fig. 4d), so $\beta$ is high here in DJF (about 10-15\%, Fig. 4e). In JJA, in the Northern Hemisphere, the high temperature and concentrated rainfall lead to more evapotranspiration, with typical values ranging from 4 to $6 \mathrm{~mm}_{\text {day }}{ }^{-1}$; values can reach $7 \mathrm{~mm}_{\text {day }}{ }^{-1}$ or more in some regions (Fig. 5c), especially in the mainly arid regions in North Africa and West and Central Asia, where values reach $8 \mathrm{~mm} \mathrm{day}^{-1}$. The stable zonal moisture fluxes distribution gives $\beta$ close to $9-15 \%$ in average regions, reaching $20 \%$ in the mainly arid regions in the Northern Hemisphere. This indicates the importance of the recycling precipitation from locally evaporated vapor in total precipitation. Considering the lack of rainfall in arid regions, this proportion is important.

To explain the role of $\beta$ in the precipitation process, the correlation coefficients between precipitation and $\beta$ in JJA (Fig. 6a) and DJF (Fig. 6b) are calculated. In Fig. 6, shading indicates significance above $90 \%$. According to Fig. 6, the relation between precipitation and recycling ratio is complex and their correlation is generally negative (Table 1). In arid regions like China-Mongolia, Central Asia, West Asia, North America, and Australia, a significant negative correlation appears in winter (DJF in the Northern Hemisphere and JJA in the Southern). This can be explained as follows. If the rainfall increases, the local temperature is reduced, and further, ET would be less and the local recycling of water vapor would decrease. In summer, there is still a weak negative correlation in arid regions, but the reduction of temperature by precipitation does not affect the ET. This indicates that in seasons with high ET values, it is possible that a negative feedback 
Fig. 3 The a annual precipitable water $\left(\mathrm{g} / \mathrm{m}^{2}\right)$, b precipitation (mm/day), $\mathbf{c}$ evapotranspiration $(\mathrm{mm} /$ day), $\mathbf{d}$ moisture flux $(\mathrm{g} / \mathrm{hPa} \mathrm{cm} \mathrm{s})$, and e recycling ratio (\%) in period of 1981-2010
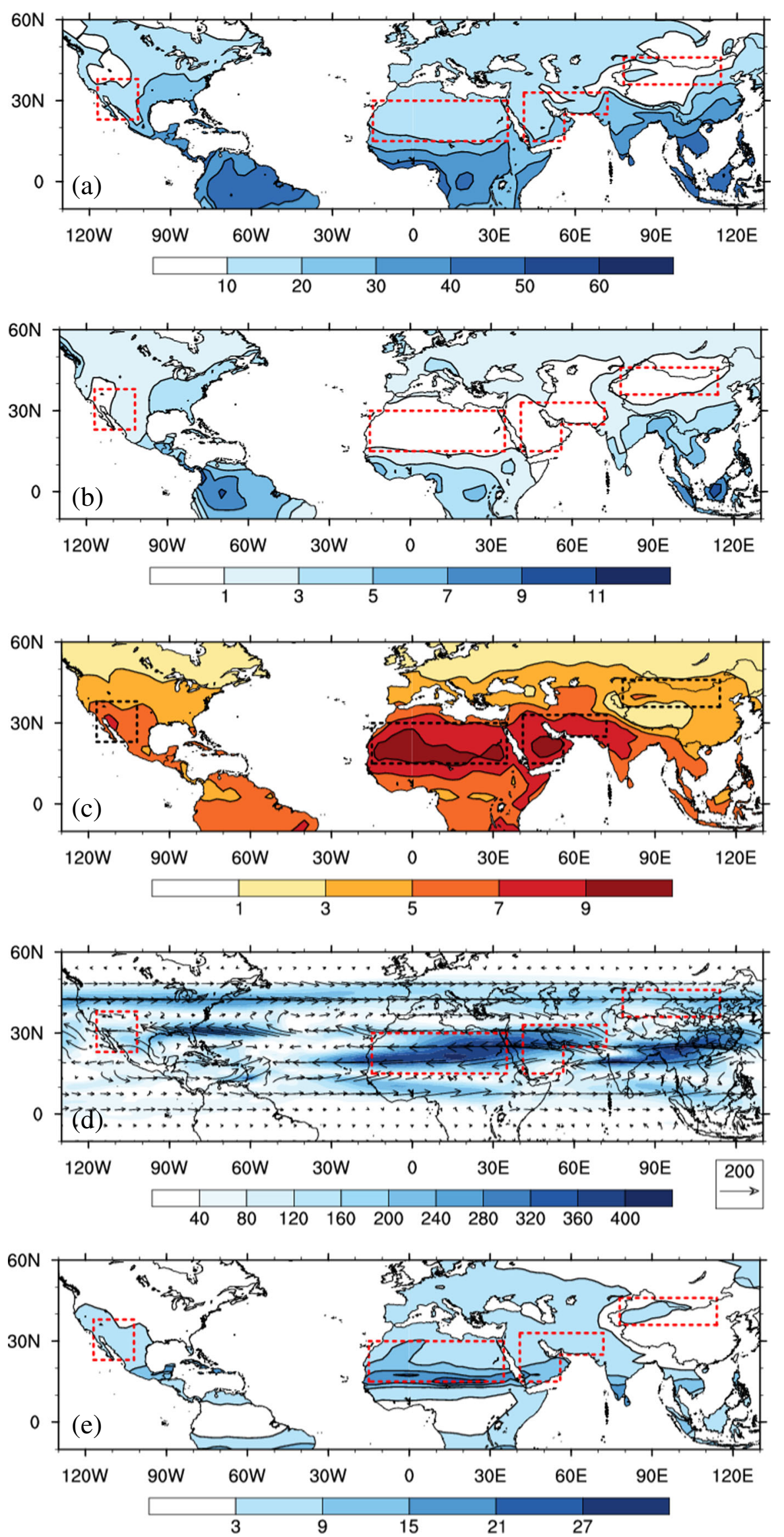
Fig. 4 The same as Fig. 3 but in DJF
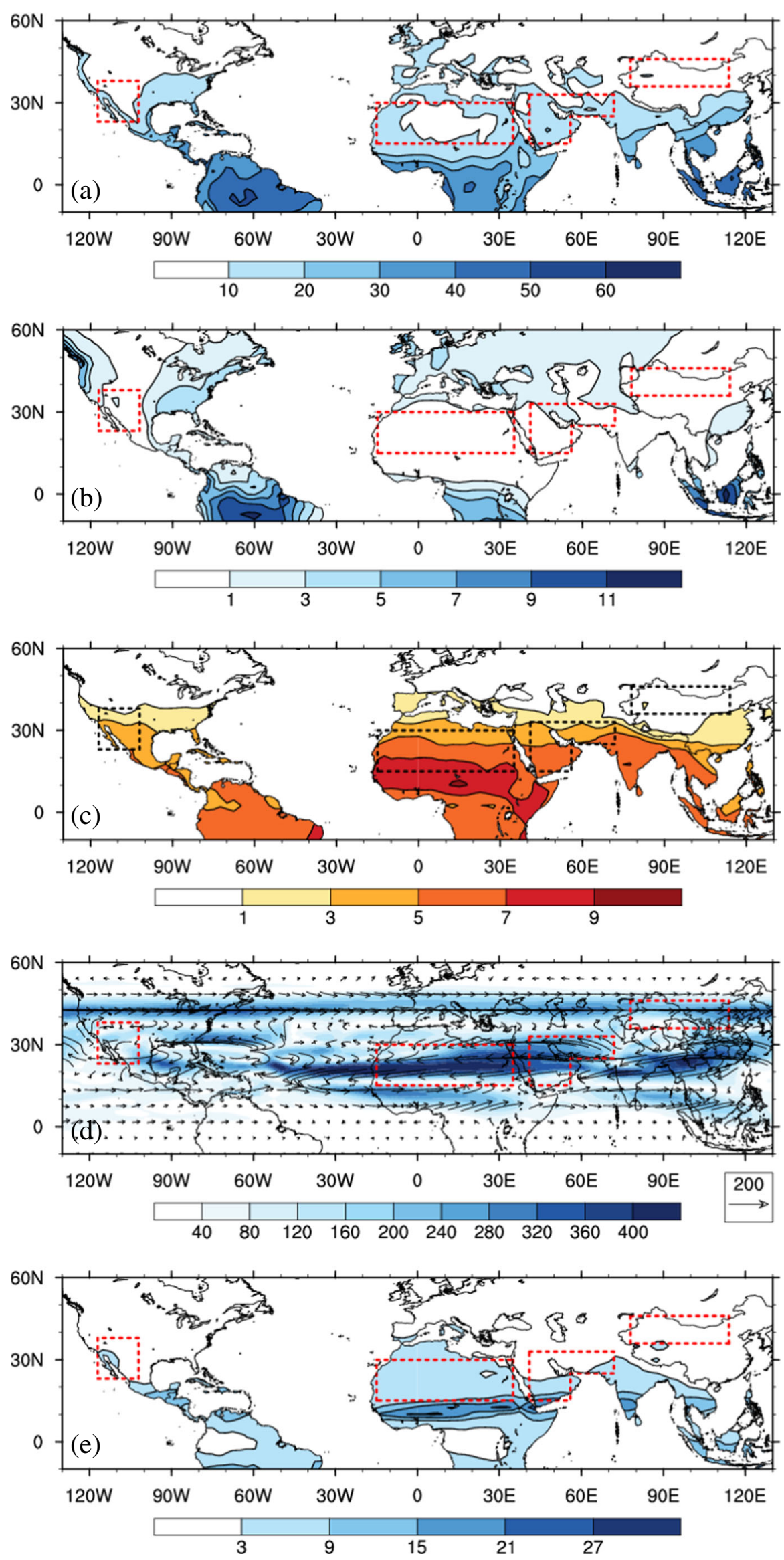

昞 Springer 
Fig. 5 The same as Fig. 3 but in JJA
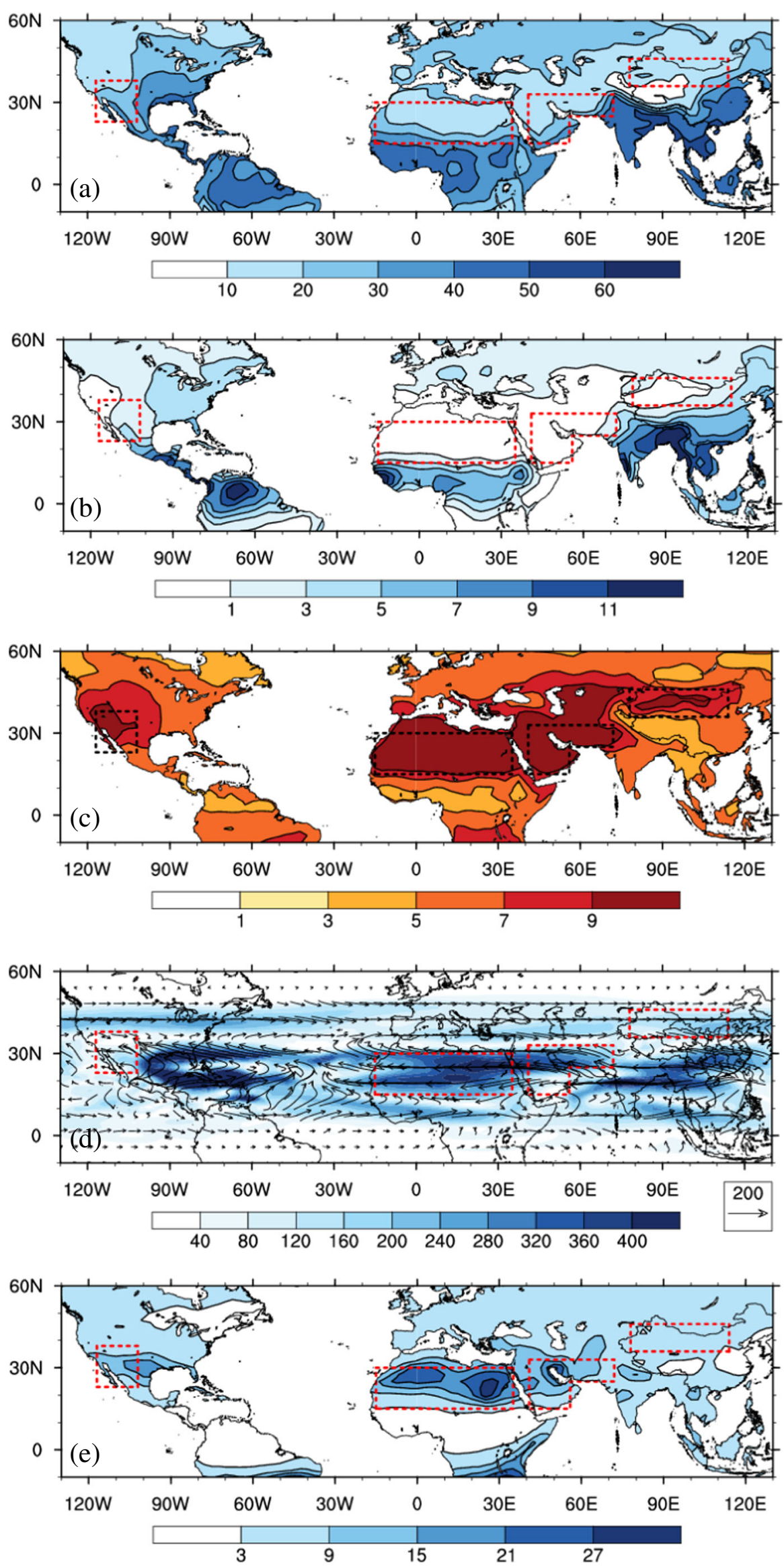

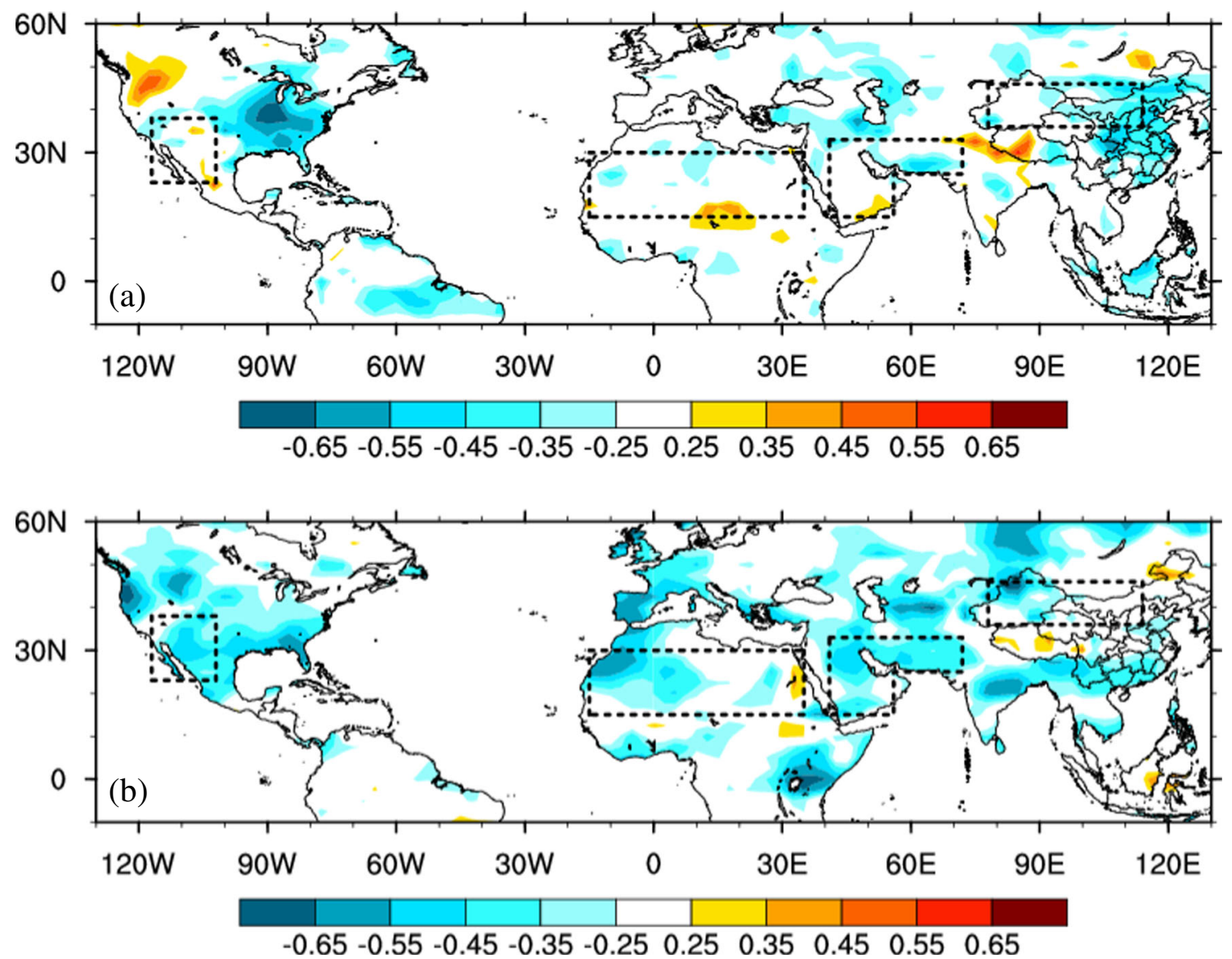

Fig. 6 The correlation between recycling ratio and precipitation from GPCP in JJA (top) and DJF (bottom) in period of 1981-2010. The shadings pass $90 \% t$ significance

recycling mechanism could promote rainfall when atmospheric conditions are dry (Dominguez and Kumar 2008).

\section{Temporal variability of recycling ratio in arid regions}

The variability of the regional recycling ratio (PRR) calculated in Eq. (6) is considered next. The interannual temporal variability over the period $1981-2010$ of precipitation $(P), \mathrm{RP}, r$, and ET is given in Fig. 7 for the four Northern Hemisphere arid regions: $\mathrm{CM}(\mathrm{a}-\mathrm{c})$, WA $(\mathrm{d}-\mathrm{f})$, NAF $(\mathrm{g}-\mathrm{i})$, and NA $(\mathrm{j}-\mathrm{l})$.

Table 1 The correlation coefficients between PRR and $P$ in CA, WA, $\mathrm{NAF}$, and NA

\begin{tabular}{lllll}
\hline & CA & WA & NAF & NA \\
\hline Annual & $-0.36^{\mathrm{a}}$ & $-0.50^{\mathrm{a}}$ & $-0.43^{\mathrm{a}}$ & -0.18 \\
DJF & $-0.49^{\mathrm{a}}$ & $-0.47^{\mathrm{a}}$ & $-0.33^{\mathrm{a}}$ & $-0.37^{\mathrm{a}}$ \\
JJA & -0.16 & -0.13 & $-0.46^{\mathrm{a}}$ & -0.06 \\
\hline
\end{tabular}

${ }^{a}$ Passing $95 \%$ significance
The left, middle, and right columns are the variations in annual, DJF, and JJA averages, respectively. The black bars are precipitation $\left(\mathrm{mm} \mathrm{day}^{-1}\right)$, the black line is RP $\left(\mathrm{mm} \mathrm{day}^{-1}\right)$, the gray bars are recycling ratio PRR, and the evapotranspiration ET is the gray line. The average values of the ratio are $4.5 \%$ (CA), $10.3 \%$ (WA), $20.4 \%$ (NAF), and $8.3 \%$ (NA), which differ from those of Bosilovich and Schubert (2002, about $15 \%$ in the USA), Dirmeyer et al. (2009, about $6.2 \%$ global), and Dominguez et al. (2006, less than $24 \%$ in the USA) and are far less than those of Burde and Zangvil (2001) and Kang et al. $(2004,2005$; about $40 \%)$. The possible reasons for these differences are the different recycling models chosen and the size of the study regions. Furthermore, the datasets used may also lead to different values of the recycling ratio. As the errors in the different values of the recycling ratio are not the main subject of this discussion, we do not pursue this issue here.

According to Fig. 7, the features of PRR vary greatly in different regions. The variability of the annual and seasonal averages in $\mathrm{CM}$ is smooth, ranging from 3.9 to $5.4 \%$ for the annual mean, 0.6 to $1.9 \%$ in DJF, and 6.9 to $11.8 \%$ in JJA, and the trend of PRR is increasing in JJA and decreasing in DJF, while the annual average has a weakly increasing 
trend (Table 2). The most obvious increasing trend in $P$ is in winter when the trend line slope is 0.03 (Table 2), while the annual average trend is smoothly increasing and the summer average is smoothly decreasing. The evapotranspiration ranges from 0.2 to $7.4 \mathrm{~mm} \mathrm{day}^{-1}$; the trend is increasing, which is consistent with the results from IPCC (AR5 2014). The correlation coefficients between PRR and $P$ are -0.36 , -0.49 , and -0.16 for the annual (Table 1 ), winter, and summer averages, respectively, and are significant at the $95 \%$ level for the annual and winter averages. But the values of $P$ in different seasons (lower than $0.45 \mathrm{~mm} \mathrm{day}^{-1}$ in winter and in summer the average value is $1.3 \mathrm{~mm}$ day $^{-1}$ ) show that the main precipitation occurs in JJA. Therefore, how the recycling precipitation works in JJA should be investigated. The mechanism can be explained as follows. Decreasing $P$ results in a higher temperature and enhanced evapotranspiration; the increased ET puts more local moisture into the atmosphere where it participates in precipitation, enhancing the recycling precipitation but will not offset the total precipitation, and the local rainfall is reduced. The reduction in precipitation in the Central U.S. Plains can be explained by this mechanism (Dominguez and Kumar 2008). In winter, $P$ increases significantly with time, while the evapotranspiration is relatively lower (less than $0.36 \mathrm{~mm}_{\text {day }}{ }^{-1}$ ); the PRR is also small, less than $2 \%$. This means that in winter, although the RP increases, the recycling precipitation can be ignored although $\mathrm{RP}$ and $P$ have the same trend.

In the WA arid region (Fig. 7d-f), both ET and PRR have an increasing trend in all time periods. The range of ET is from 3.2 to $11.9 \mathrm{~mm} \mathrm{day}^{-1}$. The seasonal variation of PRR is apparent; the range may be from less than $3 \%$ to about $25 \%$. The minimum is about $3 \%$ in DJF and the maximum may reach about $26.7 \%$ in JJA. In summer, the variations in PRR are also large: the maximum is $26.7 \%$ and minimum is $17.34 \%$. However, in winter, the range is small, from 3 to $5.5 \%$. Considering the increasing trend, the role of recycling precipitation in total rainfall becomes more important. Precipitation has a decreasing trend except in JJA. The trends are distinct and there is considerable interannual variability. The maximum and minimum precipitation can reach 1.6 and $0.6 \mathrm{~mm}$ day $^{-1}$ in DJF, with the precipitation anomaly varying from -50 to $50 \%$. Considering the trend of precipitation variation in WA is decreasing as CA. The recycling ratio and $P$ are correlated significantly in the annual and seasonal cases (annual $=-0.5 ; \mathrm{DJF}=-0.47 ; \mathrm{JJA}=-0.13$; all significant at the $95 \%$ level except in summer) (Table 1). This suggests that as the total precipitation decreases, recycling precipitation makes more of a contribution to total rainfall. A comparison with CM suggests that the decreased $P$ and increased RP and PRR in WA (Table 2) indicate that the mechanisms of precipitation recycling in different arid regions are the same.

In NAF, the situation is unlike that in CM and WA; the main precipitation is in JJA, there is an increasing trend of
Fig. 7 The annual (left), DJF (mid), and JJA (right) evolution of PRR, $P$, $\mathrm{RP}$, and $\mathrm{ET}$ in $\mathrm{CA}(\mathbf{a}-\mathbf{c})$, WA $(\mathbf{d}-\mathbf{f}), \operatorname{NAF}(\mathbf{g}-\mathbf{i})$, and NA $(\mathbf{j}-\mathbf{l})$ arid region from 1981 to 2010

annual, and JJA precipitation change but a decreasing trend in DJF. The annual, DJF, and JJA average precipitations are $0.2,0.13$, and $0.5 \mathrm{~mm}^{-1}{ }^{-1}$, respectively. However, in this region, ET is large. The maximum, minimum, and average are $11.3,5.4$, and $8.6 \mathrm{~mm} \mathrm{day}^{-1}$, respectively, and the precipitation recycling ratio ranges from 32.5 to $9.2 \%$. Unlike the Asian arid regions, the trends of PRR and ET are not the same. The annual and JJA average ET is increasing but $r$ is decreasing. Taking into account the increasing trend in recycling precipitation, this indicates that local recycling vapor is enhanced but the proportion of recycling precipitation in total rainfall is decreasing. The reason for precipitation increasing is that there is more vapor transportation into the region. In DJF, although ET and PRR are increasing, which means the recycling precipitation is enhanced and try to offset the total rainfall, the decreasing trend of precipitation is not changed. This situation is similar to CM in JJA and WA in DJF. Note that the correlation coefficients between seasonal and annual average PRR and precipitation are all significant at the $95 \%$ level, with values -0.43 (annual), -0.33 (DJF), and -0.46 (JJA) (Table 1). This means that changes of total rainfall are sensitive to variations in the recycling precipitation.

In the NA arid region, the annual, DJF, and JJA averages of $P$ are $1.1,1.0$, and $1.4 \mathrm{~mm} \mathrm{day}^{-1}$, respectively, and this is the region of most abundant rainfall of the four. The correlation between $P$ and PRR is the least significant of that in the four chosen regions, while the coefficients for the annual and summer cases are not significant. This indicates that $P$ in NA is not sensitive to PRR. But the trends of the variables are similar with those in NAF. The trends of $P$ and PRR are reduced in the annual and JJA average. Values of PRR range from 1.6 to $16.8 \%$, with an average value of $8.3 \%$, similar to the results of previous studies (Bosilovich and Schubert 2002: about $10 \%$; Dominguez and Kumar 2008: about $8 \%$ ). ET has a similar seasonal variation to that in CM; the maximum appears in JJA and averages $8.4 \mathrm{~mm}$ day $^{-1}$ while the minimum $\left(1.3 \mathrm{~mm}_{\text {day }}{ }^{-1}\right)$ is in winter. The annual and seasonal variations of ET all have an increasing trend. This means that the recycling moisture that evaporates into the atmosphere is increasing. The decreasing tendencies of $P$, RP (JJA), and PRR may be explained as follows. In the warm season, the reduced precipitation enhances the surface heating, leading to more evapotranspiration, so more locally evaporated moisture will enter the atmosphere, but the extra water vapor does not convert into precipitation and counter the reduced precipitation. This is just like CM in JJA and WA and NAF in DJF. 


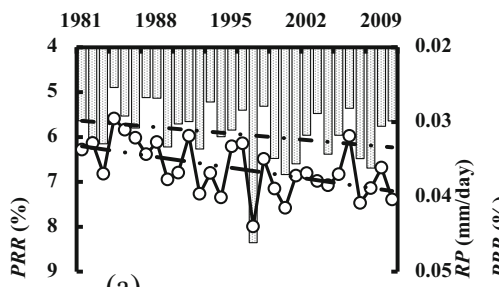

0.9 (a)

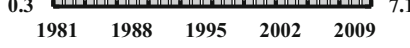

$\begin{array}{lllll}1981 & 1988 & 1995 & 2002 & 2009\end{array}$

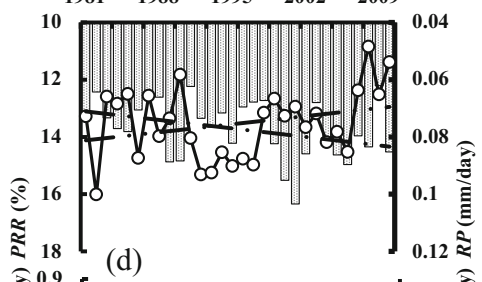

$\frac{1981}{1988}$

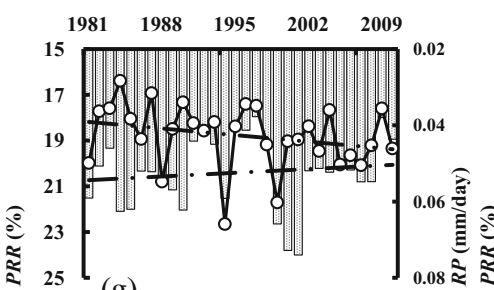

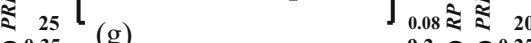

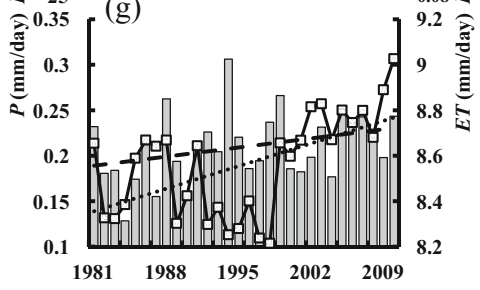

$\begin{array}{ccccc}1981 & 1988 & 1995 & 2002 & 2009 \\ 1981 & 1988 & 1995 & 2002 & 2009\end{array}$

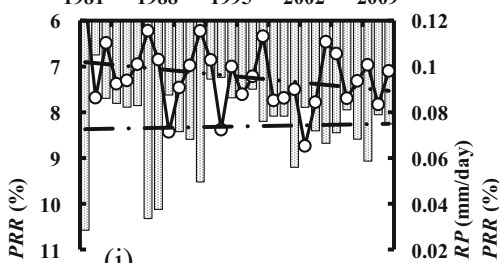

11 (j)

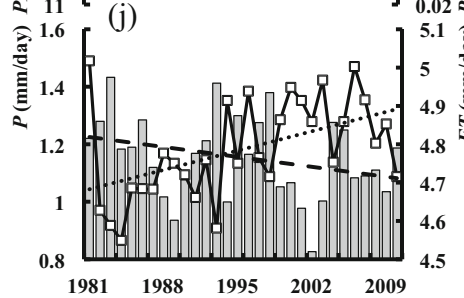

0.15
0.1
0.05
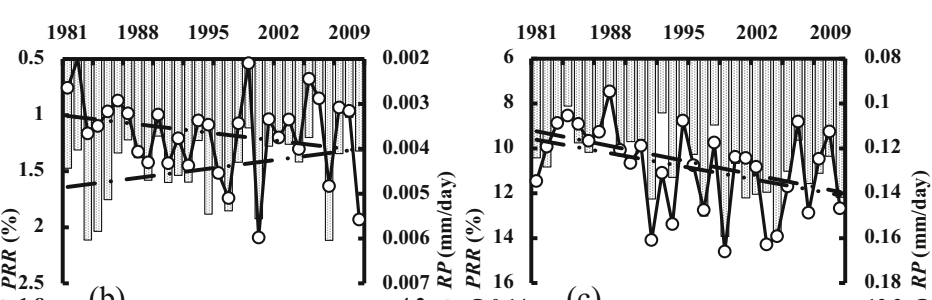

(b)

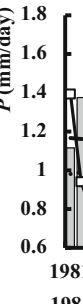

(c)

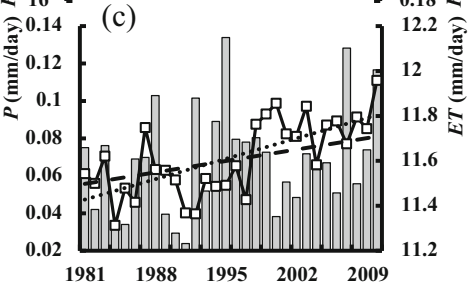

$\begin{array}{lllll}1981 & 1988 & 1995 & 2002 & 2009\end{array}$

$\begin{array}{lllll}1981 & 1988 & 1995 & 2002 & 2009\end{array}$

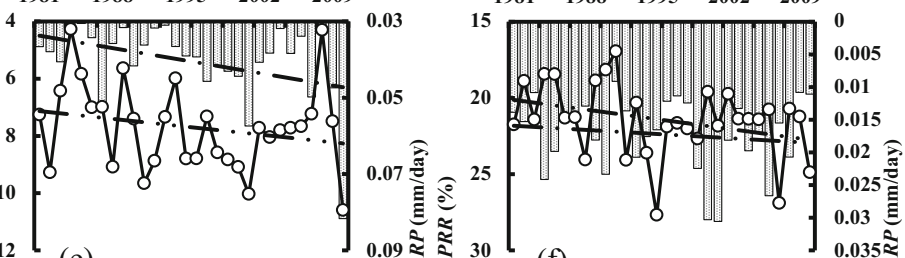

(1)

(1)
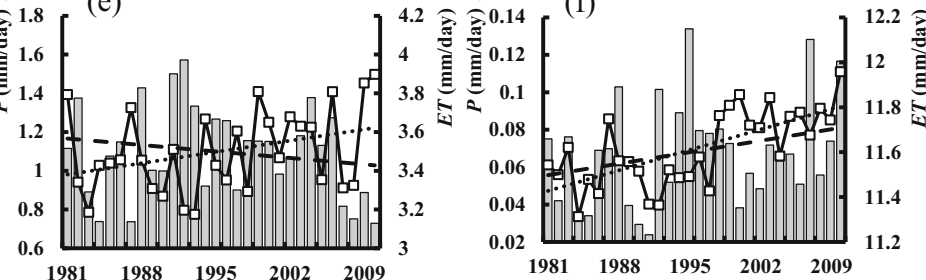

$\begin{array}{lllll}1981 & 1988 & 1995 & 2002 & 2009\end{array}$

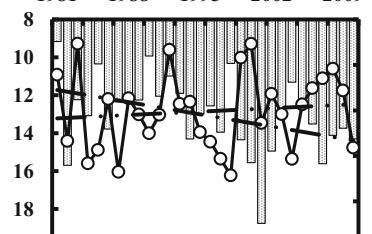

0.025

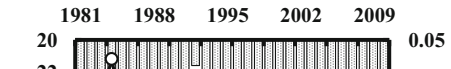

(h)

0.25
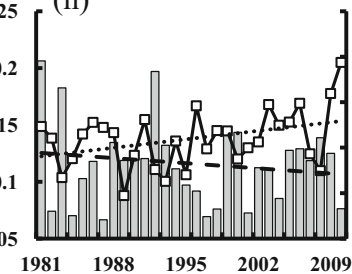

$\begin{array}{lllll}1981 & 1988 & 1995 & 2002 & 2009\end{array}$

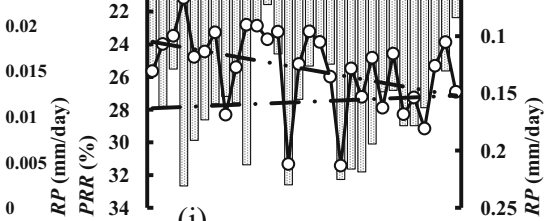

(i)

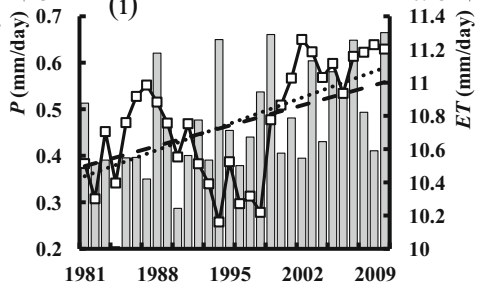

1.5 [||[|| ||

$\begin{array}{lllll}1981 & 1988 & 1995 & 2002 & 2009\end{array}$

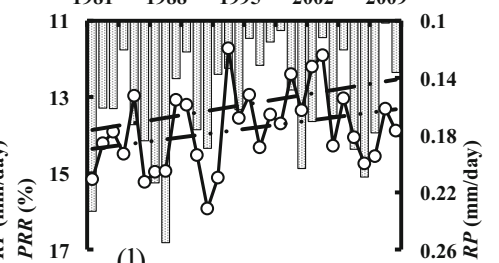

(k)

(l)

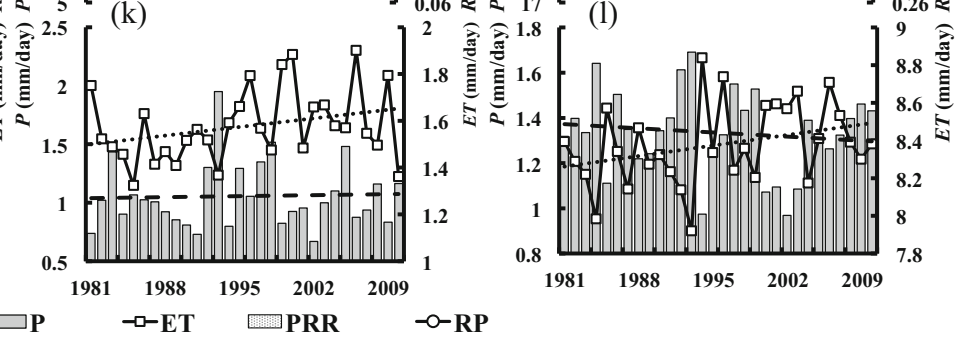


Table 2 The trends of PRR, $P$, ET, and RP in CA, WA, NAF, and NA

\begin{tabular}{llllll}
\hline & & PRR & $P$ & ET & RP \\
\hline CA & Annual & 0.2 & 0.01 & $0.09^{\mathrm{a}}$ & 0.00 \\
& DJF & $-0.11^{\mathrm{a}}$ & 0.03 & -0.00 & 0.00 \\
& JJA & $0.93^{\mathrm{a}}$ & -0.02 & $0.15^{\mathrm{a}}$ & 0.00 \\
WA & Annual & $0.43^{\mathrm{a}}$ & $-0.04^{\mathrm{a}}$ & $0.11^{\mathrm{a}}$ & -0.00 \\
& DJF & $0.62^{\mathrm{a}}$ & -0.04 & 0.08 & 0.00 \\
& JJA & 0.38 & 0.00 & $0.13^{\mathrm{a}}$ & 0.00 \\
NAF & Annual & -0.23 & 0.01 & $0.14^{\mathrm{a}}$ & 0.00 \\
& DJF & $0.92^{\mathrm{a}}$ & -0.00 & $0.1^{\mathrm{a}}$ & 0.00 \\
& JJA & $-0.26^{\mathrm{a}}$ & 0.06 & $0.22^{\mathrm{a}}$ & $0.01^{\mathrm{a}}$ \\
\multirow{4}{*}{ NA } & Annual & -0.04 & -0.05 & $0.07^{\mathrm{a}}$ & -0.00 \\
& DJF & 0.02 & 0.01 & 0.05 & 0.00 \\
& JJA & -0.45 & -0.02 & 0.07 & -0.01 \\
\hline
\end{tabular}

${ }^{\text {a }}$ Passing $95 \%$ significance

\section{Discussion and conclusion}

Water recycling couples the land, atmosphere, and other components of the earth system into a unified system and maintains the system in a dynamic balance. This work investigates the water recycling on climate scale, calculated and compared features of water recycling in four arid regions in Northern Hemisphere. However, considering the regional features, unlike precipitation and precipitable water, $\beta$ in arid regions is not lower than in regions with abundant rainfall, which ranges $10-15 \%$. This indicates that the local recycling ratio is positively correlated with evapotranspiration, which is dominated by radiation and dynamic conditions. This suggests a mechanism in which reduced precipitation leads to enhancement of the local recycling precipitation. In other words, precipitation has self-make up effects.

The PRR was calculated for four arid regions, CM, WA, NAF, and NA, with annual average of 5, 12, 18, and $8 \%$, respectively. The ratio has an increasing trend in the Asian arid regions and a decreasing trend in NA and NAF in last 30 . And there is a significant seasonal variation of PRR, higher in JJA and lower in DJF in all four regions. Considering the season of precipitation concentrated (JJA for CM, NAF, and NA; DJF for WA), the different trends of precipitation recycling ratio and variables also imply that the different relation between PRR and precipitation in each regions. In CM and WA, PRR increases significantly, and it indicates the decreasing rainfall in $\mathrm{CM}$ and WA is not controlled by local precipitation recycling but by reduced advection vapor (Xu et al. 2016). The increasing PRR shows that the recycling precipitation is a kind of self-make up mechanism for total rainfall when precipitation decreases. In NA, PRR and total rainfall decrease and ET increases. It indicates more evaporated vapor passes into the atmosphere but does not convert into actual precipitation to offset the reduced rainfall. However, in NAF, like NA, the trend of recycling ratio is decreasing. But precipitation and ET increase. It implies the property of local evapotranspiration vapor in total rainfall decreases, and increasing precipitation is affected by enhanced advection vapor.

It should be pointed out that the precipitation recycling also has a robust impact on the precipitation on weather scale, for example, the extreme precipitation which is mainly related to the circulation and vapor transport anomaly (Krichak et al. 2014). However, Sodemann et al. (2006) used water vapor tracers in CHRM with a $25-50-\mathrm{km}$ horizontal resolution to assess the contribution of moisture from local evaporation and other vapor sources to flood events in Central Europe, in two flood cases in 2002 and 2005. Their result indicated that land surface vapor (precipitation recycling) has a notable contribution in Central Europe extreme precipitation events. Huang and Cui (2015) used a Lagrangian method to estimate extreme precipitation in Sichuan, West China and found that the main vapor source causing heavy precipitation is vapor that transported from Indian Ocean and the local moisture contribution still reaches to $32 \%$. Dominguez and Kumar (2008) also pointed out that the precipitation recycling ratio change was more of high frequency when extreme precipitation happened in Central U.S. Plains. Furthermore, Raddatz (2005) suggested that there is an intra-summer feedback between evapotranspiration and rainfall. This feedback affects moisture and energy from the surface water budget to the atmospheric water balance and will decide whether dry and wet summers maintained. The mean summer recycling ratio attributable to evapotranspiration within target region is a factor for determining whether an area had a dry, normal, or wet summer. Precipitation in target region is predominately convective. Namely, the water vapor is converted into rain less frequently over drought areas than over areas which received normal rainfall and more frequently over the pluvial areas (Raddatz 2005). Thus, the influence of precipitation recycling is not only on climate mean but also on weather events.

Another issue is that the land use and cover also strongly influence the PRR via affecting evapotranspiration. Vervoort et al. (2009) found PRR in large irrigation region in Australia ranges from 10 to $20 \%$, which is larger than the ratio in grass underlying region. Harding and Snyder (2014) investigated the impact of irrigation on precipitation recycling using Weather Research and Forecast Model (WRF) in North America and found that evapotranspiration increased by $4 \%$ approximately and precipitation increased by $1 \%$ due to irrigation expansion. This irrigation impact on PRR can be 
explained in a sense that irrigation increases soil moisture and supplies abundant vapor for evapotranspiration, which enhances the precipitation recycling and precipitation. The observations show that the irrigation areas are intensively expanding from 1960s in arid region of North Africa and West Asia (Jomaa et al. 2015; Martín-Queller et al. 2010), which consist with PRR increases in this study.

In additional, according to Eqs. (9), (11), and (13), ET should increase with the temperature and radiation, which may be caused by land use/cover changes. A lot of observations show that the land use/cover has significantly changed in arid region. Chuluum and Ojima (2002) reported that the movement of population changed the land use in Asian arid/semiarid region from 1960s. Widespread reduction of grasslands and expansion of croplands cause anabatic desertification in ChinaMongolia. Paz-Kagan et al. (2014) evaluated the soil quality index and aboveground net primary productivity by comparing the magnitude and the direction of the land use changed in Negev Desert West Asia. The expansion of large-scale agricultural land in North Africa and the area of forest cover in 1990s reduced to $13 \%$, and the Lake Malawi level was about $1 \mathrm{~m}$ lower comparing with the amount in 1960s in Sub-Saharan Africa (Calder et al. 1995). Those land use/cover changes will affect temperature and radiation. Bayer et al. (2012) analyzed the regional climate feedback to land use changes in SubSaharan, Europe, Amazon, and South Asia, and the results indicated that land use changes, like expansion of arable land and desert, would enhance the surface temperature. Liang et al. (2010) suggested that land use/cover changes, like grass degeneration and irrigation expansion, would change surface albedo and outgoing radiation, which contribute substantially to land warming trends. Generally speaking, land cover/use changes in arid regions increase air temperature and the increasing temperature enhanced the evapotranspiration, further enhancing the vapor recycling.

This study investigated mean change of PRR on climate scale. PRR in weather events under land surface changes is our future work. Particularly, the showery precipitation is frequent in those target arid regions in this study. It is still an open question what is the contribution of PRR on annual and seasonal scale. Although the evapotranspiration changed in this study included the influence from land use/cover changes indirectly via the temperature and radiation changes, the impact of land use/cover changes, like irrigation extension, on PRR in arid regions remains uncertain. Comparing observations with weather model simulations to quantitatively evaluate vapor changes on local and large scale will benefit for energy and water recycling on more large scale. Therefore, PRR changes considering land use and cover including irrigation in arid is our further work.
Further, another notable issue is the estimation of evapotranspiration that has large uncertainty, which must affect the estimation of precipitation recycling; hence, more accredited precipitation recycling depends on accuracy of evapotranspiration estimation.

Acknowledgments This work is supported by the National Science Foundation of China (No. 41471034, No. 91437217, No. 41440035 and No. 41661144017), Industry Special Projects of CMA (GYHY201506001, CCSF2014), and the Fundamental Research Funds for the Central Universities (lzujbky-2016-194; lzujbky-2015-k03).

Open Access This article is distributed under the terms of the Creative Commons Attribution 4.0 International License (http:// creativecommons.org/licenses/by/4.0/), which permits unrestricted use, distribution, and reproduction in any medium, provided you give appropriate credit to the original author(s) and the source, provide a link to the Creative Commons license, and indicate if changes were made.

\section{References}

Benton GS, Estoque MA (1954) Water-vapor transfer over the North American continent. J Meteorol 11(6):462-477

Budyko MI (1974) Climate and life. Int Geophys Ser, 18

Brubaker KL, Entehabi D, Eagleson PS (1993) Estimation of continental precipitation recycling. J Clim 6:1077-1089. doi:10.1175/15200442(1993)006<1077:EOCPR >2.0.CO;2

Bisselink B, Dolman AJ (2008) Precipitation recycling: moisture sources over Europe using ERA-40 data. J Hydrometeorol 10:1073-1083. doi:10.1175/2008JHM962.1

Bosilovich MG, Schubert SD (2002) Water vapor tracers as diagnostics of the regional hydrologic cycle. J Hydrometeor 3:149-165. doi:10.1175/1525-7541(2002)003<0149:WVTADO >2.0.CO;2

Burde GI, Zangvil A (2000) The estimation of regional precipitation recycling. Part I: review of recycling models. J Clim 14(2):24972508. doi:10.1175/1520-0442(2001)014<2497:TEORPR >2.0. $\mathrm{CO} ; 2$

Burde GI, Zangvil A (2001) The estimation of regional precipitation recycling. Part II: a new recycling model. J Clim 14(2):25092527. doi:10.1175/1520-0442(2001)014<2509:TEORPR >2.0. $\mathrm{CO} ; 2$

Bayer LB, van den Hurk B, Strengers BJ et al (2012) Regional feedbacks under changing climate and land-use conditions. Earth System Dynamics Discussions 3(1):201-234. doi:10.5194/esdd-3-2012012

Calder IR, Hall RL, Bastable HG et al (1995) The impact of land use change on water resources in sub-Saharan Africa: a modelling study of Lake Malawi. J Hydrol 170(1-4):123-135. doi:10.1016/00221694(94)02679-6

Dirmeyer PA, Schlosser CA, Brubaker KL (2009) Precipitation, recycling, and land memory: an integrated analysis. J Hydrometeorol 10:278-288. doi: 10.1175/2008JHM1016.1

Dominguez F, Kumar P, Liang XZ et al (2006) Impact of atmospheric moisture storage on precipitation recycling. J Clim 19:1513-1530. doi:10.1175/JCLI3691.1

Dominguez F, Kumar P (2008) Precipitation recycling variability and ecoclimatological stability - a study using NARR data. Part I: central U.S. Plains Ecoregion J Climate 21(20):5165. doi:10.1175/2008 JCLI1756.1

Dingman SL (1994) Physical hydrology. Prentice Hall, Englewood Cliffs $646 \mathrm{PP}$ 
Eltahir EB, Bras RL (1994) Precipitation recycling in the Amazon basin. Quart J Roy Meteor Soc 120:861-880. doi:10.1256/smsqj.51805

Eltahir EB, Bras RL (1996) Precipitation recycling. Rev Geophys 34: 367-378. doi:10.1029/96RG01927

El-tahir MI, Omojola MF, Malatani T, Al-Saigh AH, Ogunbiyi OA (1992) Hydatid disease of the liver: evaluation of ultrasound and computed tomography. Br J Radiol 65(773):390-392

Fu Q, Johanson CM, Wallace JM, Reichler T (2006) Enhanced midlatitude tropospheric warming in satellite measurements. Science 312:1179-1179. doi:10.1126/science.1125566

Guo YP, Wang CH (2014) Trends in precipitation recycling over the Qinghai-Xizang Plateau in last decades. J Hydrol 517(19):826835. doi:10.1016/j.jhydrol.2014.06.006

Harding KJ, Snyder PK (2014) Modeling the atmospheric response to irrigation in the Great Plains. Part II: the precipitation of irrigated water and changes in precipitation recycling. J Hydrometeorol 601(13):1687-1703. doi:10.1175/JHM-D-11-099.1

Hulme M, R Marsh (1990) Global mean monthly humidity surface for 1930-59, 1960-69 and projected for 2030. Report to UNEP/GEMS/ GRID, Climate Research Unit, University of East Anglia, Norwich

Huang Y, Cui X (2015) Moisture sources of an extreme precipitation event in Sichuan, China, based on the Lagrangian method. Atmos Sci Lett 16(2):177-183. doi:10.1002/asl2.562

IPCC (2014) Climate change 2013: the physical science basis, observations: atmosphere and surface. Page: $201-220$

Jomaa I, Myriam SS, Jaubert R (2015) Sharp expansion of intensive groundwater irrigation, semi-arid environment at the northern Bekaa Valley Lebanon. Nat Resour 06(6):381-390. doi:10.4236 /nr.2015.66036

Kang H, Gu X, Zhu C et al (2004) Precipitation recycling in southern and central China. Chinese J Atmos Sci 28(6):892-900

Kang H, Gu X, Fu X et al (2005) Precipitation recycling over the northern China. J Appl Meteorol Sci 16(2):139-147

Krichak SO, Barkan J, Breitgand JS et al (2014) The role of the export of tropical moisture into midlatitudes for extreme precipitation events in the Mediterranean region. Theor Appl Climatol 121(3):1-17. doi: $10.1007 / \mathrm{s} 00704-014-1244-6$

Liang S, Kustas W, Schaepman-Strub G, Li X (2010) Impacts of climate change and land use changes on land surface radiation and energy budgets. IEEE Journal of Selected Topics in Applied Earth Observations and Remote Sensing 3(3):219-224. doi:10.1109 /JSTARS.2010.2053570

Martín-Queller E, Moreno-Mateos D, Pedrocchi C et al (2010) Impacts of intensive agricultural irrigation and livestock farming on a semi-arid Mediterranean catchment. Environ Monit Assess 167(1-4):423435. doi:10.1007/s10661-009-1061-z

Paz-Kagan T, Shachak M, Zaady E et al (2014) Evaluation of ecosystem responses to land-use change using soil quality and primary productivity in a semi-arid area, Israel. Agric Ecosyst Environ 193:9-24. doi:10.1016/j.agee.2014.04.024

Penman HL (1948) Natural evaporation from open water, bare and grass. Proc R Soc LondSer A 193:120-145
Raddatz RL (2005) Moisture recycling on the Canadian prairies for summer droughts and pluvials from 1997 to 2003. Agric For Meteorol 131(1):13-26. doi:10.1016/j.agrformet.2005.04.007

Schär C, Lüthi D, Beyerle U et al (1999) The soil-precipitation feedback: a process study with a regional climate model. J Clim 12(3):722741. doi:10.1175/1520-0442(1999)012<0722:TSPFAP $>2.0 . C O ; 2$

Shuttleworth WJ (1993) Maidment DR (Ed.) Evaporation. McGraw-Hill, New York, pp. 4.1-4.53 (Chapter 4)

Smith TM, Arkin PA, Ren L, Shen S (2012) Improved reconstruction of global precipitation since 1900. J Atmos Ocean Technol 29:15051517. doi:10.1175/JTECH-D-12-00001.1

Thornthwaite CW (1948) An approach toward a rational classification of climate. Geogr Rev 38(1):55-94

Trenberth KE (1998a) Atmospheric moisture recycling: role of advection and local evaporation. J Clim 12:1368-1381. doi:10.1175/15200442(1999)012<1368:AMRROA>2.0.CO;2

Trenberth KE (1998b) Atmospheric moisture residence time and cycling: implication for rainfall rates and climate change. Climate Change 39:667-694. doi:10.1023/A:1005319109110

Valiantzas JD (2006) Simplified versions for the Penman evaporation equation using routine weather data. J Hydrol 331(3-4):690-702. doi:10.1016/j.jhydrol.2006.06.012

Vervoort RW, Torfs P, Van Ogtrop FF (2009) Irrigation increases moisture recycling and climate feedback. Aust J Water Resour 13:121

Wang CH, Guo Y (2012) Precipitable water conversion rates over the Qinghai-Xizang (Tibet) Plateau: changing characteristics with global warming. Hydrol Process 26:1509-1516. doi:10.1002/hyp.8246

Sodemann H, C Schwierz, H Wernli, (2006) Moisture sources for an extreme precipitation event in central Europe simulated with a mesoscale model. AGU Fall Meeting. AGU Fall Meeting Abstracts, 1607-7962/gra/EGU06-A-07195

Wentz FJ, Ricciardulli L et al (2007) How much more rain will global warming bring? Science 317(5835):233-235. doi:10.1126/science.1140746

Willett KM, Jones PD, Gillett NP, Thorne PW (2008) Recent changes in surface humidity: development of the HadCRUH dataset. J Clim 21: 5364-5383. doi:10.1175/2008JCLI2274.1

Xu D, Li R, Wang C (2016) Characteristics of precipitation and relationship with vapor transport in Asia-Africa typical arid region under global warming. Climatic and Environmental research (In Chinese). doi:10.3878/j.issn.1006-9585.2016.15256

Yi L, Tao S (1997) Role of the standing and the transient eddies in atmospheric water cycle in the Asian monsoon region. Act A Meteorological Sinica 55(5):532-544 (in Chinese)

Zangvil A, DH Portis, PJ Lamb, (1993) Diurnal variations in the water vapor budget components over the Midwestern United States in summer 1979. Interactions Between Global Climate Subsystems the Legacy of Hann, 53-63. doi: 10.1029/GM075p0053

Zhang S, Tao S (2001) Hydro balance of earth-atmosphere system in the Yarlung Zangbo River. Adv Water Sci 12(4):509-515 (In Chinese) 